different races occupying precisely similar habitats show strikingly different colouration, but colour clines run in different directions in different groups. The topic is a fascinating one, though it has been extensively neglected. The erection of Hershkovitz's hypothesis that colour change is constant in direction and irreversible should stimulate evolutionary

\section{Seed dormancy and germination}

The Physiology and Biochemistry of Seed Dormancy and Germination. Edited by A. A. Khan. Pp. 447. (Elsevier/North-Holland: Amsterdam, New York and Oxford, 1977.) \$65.95; Dfl. 162.

THIs multiauthor volume must surely become regarded as the standard text on this subject, at least for the time being. The editor has managed to bring together a more representative and distinguished panel of authors than had previously been achieved in this area, and most of the contributions are of a very high standard, written in a clear style with commendable economy of words. Particularly outstanding are a gem of an prefatory chapter by K. V. Thimann and a review of the effects of gibberellin on barley aleurone tissue, in the chapter by R. L. Jones and $\mathbf{J}$. L. Stoddart, which summarises a weighty literature by means of two pages of text and two figures.

A weakness in the book is that the editor has allowed his contributors to define their own terms, so that the reader is able to dig out, for example, a number of different definitions of dormancy. As this may confuse anyone who reads more than one chapter, it surely would have been desirable for all of the contributors to decide on an agreed form of words for important definitions, and for these definitions to be made at the beginning of the book together with a clear statement of any differences of opinion with respect to the definitions. Confusion about dormancy arises because there are two distinct types: 'imposed dormancy' in which germination fails to occur because of the absence of suitable conditions (for example, the low moisture content of seeds in the seedsman's packet); and 'true dormancy' in which germination fails to occur in conditions which are favourable for the continued growth of the germinated seedling. In addition I deplore the use of the term 'seed' outside of its strict botanical definition; this can lead to unacceptable imprecision in scientific writing.

The first main part of the book, "General Topics", commences rather unsurely in chapters by R. C. Jann and biologists to examine the ecological correlates of colouration in an attempt to find a more satisfactory explanation.

T. H. Clutton-Brock

T. H. Clutton-Brock is a Senior Research Fellow in the Behavioural Ecology Group of the King's College Research Centre, University of Cambridge, UK.

R. D. Amen on "What is Germination?" and by A. A. Khan on "Seed Dormancy: Changing Concepts and Theories". Their attempts to produce all-embracing hypotheses to account for dormancy and germination are less than entirely convincing, particularly as later authors emphasise the paucity of knowledge about so many aspects of this subject. M. G. Nikolaeva brings the reader back to earth with a well written chapter on "Factors Controlling the Seed Dormancy Pattern". It is a real pleasure to see that a summary account of her numerous contributions is now widely available in this form.

The second part of the book, which deals with "Hormones and Seed Germination", has been written with competence and flair, but scems to suggest that investigations on gibberellins (R. L. Jones and J. L. Stoddart) and abscisic acid (D. C. Walton) have proceeded rather more expeditiously than those on cytokinins (T. H. Thomas) and ethylene (D. L. Ketring).

Part three commences with chapters on the effects of light and of chilling in breaking dormancy, written by W. Vidaver and by S. Lewak and R. M. Rudnicki, respectively. It seems unfortunate that the latter authors have rather overemphasised their own material, apple seed, the somewhat weak embryo dormancy of which may not be typical of seeds which require chilling. Part three closes with three good chapters on applied aspects of seed germination: one by J. D. Maguire on seed quality; one on stress by W. Heydecker, which is full of valuable information; and one by $A$. A. Khan on preconditioning.

Part four, on "Molccular and Metabolic Aspects of Seed Germination", opens with three excellent and concise chapters on "Nucleic Acids and Seed Germination" (D. J. Osborne), "Stored Messenger RNA and Seed Germination" (L. S. Dure, III) and "Protein Synthesis and Seed Germination" (J. D. Brooker, C. P. Cheung and A. Marcus); and continues on a high level in a chapter on "Metabolic Control of Germination" (A. M. Mayer), which picks out some important aspects of control. E. H. Roberts and R. D. Smith have written a clear account in support of their hypothesis that the pentose phosphate pathway plays a central role in the breaking of dormancy. Although their proposals are of considerable interest their data fall short of being conclusive for any species and it may be premature to consider the applicability of the hypothesis to a wide range of species. Unfortunately the book ends on a low note in a poorly written chapter on "Hormonal Regulation of Nucleic Acids and Proteins in Germination", by K-L. Tao and A. A. Khan, which seriously overlaps some earlier chapters and which provides a badly expressed jumble of information. Any glutton for punishment who reaches the top of $\mathrm{p} 423$ will find the following sentence: "Isocitratase is an important enzyme in Krebs cycle."

The quality of the book is slightly marred by the occurrence of rather more typographical errors than one would expect. It is a pity that there is no author index; had space been saved by the provision of one consolidated list of references, an author index could have been produced without any increase in pagination. However, the faults seem fairly negligible when balanced against the general excellence of the work.

J. W. Bradbeer

J. W. Bradbeer is Professor of Botany a! King's College, University of London, $U K$.

\section{SCIENTIFIC - BOOKS}

H. K. LEWIS can supply works in all branches of Pure and Applied Science. Catalogues on request. Please state interests.

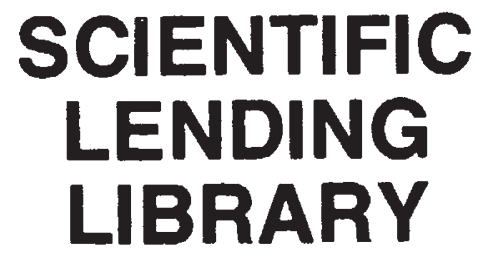

Annual Subscription from $\mathbf{8 7 . 0 0}$. (Available in U.K. only)

Reduced rates for multiple subscriptions.

Prospectus post free on request.

Quarterly List of New Books and new editions added to the Library sent post free to subscribers regularly.

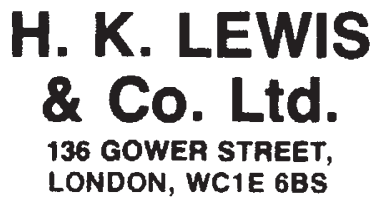

Twephone: 01-387 4282 Tetegrams: "Pubilcevit, London, wC1E 6BS."

Circle No. 09 on Reader Enquiry Card. 